\title{
Ricardo Falla Barreda, R. (2017). Poesía abierta. Poemas reunidos. Lima. Fondo Editorial de la Universidad Nacional Mayor de San Marcos
}

Pequeña historia de conciencia (1971) se encuentra entre los libros de poemas que abren una década de reconocida importancia por traer al quehacer literario peruano la presencia y voz de nuevos sujetos y distintas poéticas. Con él, Ricardo Falla Barreda inicia un camino de poesía ininterrumpido a lo largo de décadas y que continúa hasta el presente.

Testimonio de este permanente trabajo en el que se registran y se expanden algunos temas y van surgiendo nuevos motivos, son los libros Contra viento y marea (1973), Mi capital (1979), Poesía abierta (1982), Interludios (2006) y ahora esta reunión de textos que incluye Otros poemas (2017), muestra de una personal, definida poética reunida en cerca de 300 páginas.

Más que compendio, un amplio panorama en el que queda explícita una poética de variada tesitura y elaborada formulación que le hace decir al poeta Alejandro Romualdo, autor del prólogo a Mi capital (1979):

Es una poesía culta, de espectro ambicioso, que le permite plantar rosales en el pecho lacerado de la historia contemporánea [...] Sus poemas son dominios subversivos del símbolo y la metonimia [...] Es la vida misma, pero escrita con experiencia fantástica, es decir, no descrita ni ilustrada [...] entre cuyas páginas reposa el ramo encantado de la inteligencia poética, signo de su esplendor imaginativo, imagen de su claridad conceptual.

Textos que subvierten la realidad directamente observada tanto por la naturaleza de las motivaciones como por la intervención de los recursos formales puestos al servicio de la exposición poética. Estos méritos son señalados por el poeta y maestro universitario Manuel Velásquez Rojas, quien en la presentación de Interludios (2006) califica a los libros que lo antecedieron - Mi capital y Poesía abierta - como libros de madurez. 
Con agudeza, el maestro Velásquez Rojas advierte que "de un primer registro de manifestaciones formales de la poética del 70, Ricardo Falla conserva el coloquialismo", y luego distingue: "pero no es la conversación que en una tradicional calle de Lima se puede escuchar. No. Ahora es un diálogo con los íconos preferidos [...] Coloquio que recrea un espacio cultural para el ícono y su trascendencia".

Este rasgo distintivo es muy importante de resaltarse por ser clara manifestación de la diversidad de motivaciones que animan al creador y su capacidad de dialogar con íconos de múltiples etapas históricas y espacios culturales.

Así, por ejemplo, lo observamos en coloquio con personajes tales como la autora de la "Epístola a Belardo", la poetisa Amarilis del siglo XVII, en el poema "Epístola a Amarilis" ("Te veo Amarilis / porque eres una surtidora de poemas / porque eres una surtidora /... Te leo Amarilis / en estos años que transito al irremediable / destino de la soledad en piedra / y te vuelvo a imaginar escribiendo / sobre las tensiones entre el morir y el nacer / entre el orto y el cenit / la claridad del alma y la palidez del rostro / porque en los resplandores matinales / te alojaste / enramada / como ave dejando una estela ardiente"); con un personaje homérico, como en el poema "Bajo el viento de Ulises"; con el pensador peruano José Carlos Mariátegui, en "Escena contemporánea" ("Matriz de mi tiempo / cuídate de los que te aman / para que el hombre no sea polvo de otro hombre / ni piedra adscrita a cementerio alguno") ; o el poema dedicado al Señor de Sipán, en "Variaciones ante un mundo de bronce"; dialogar con el personaje cervantino en "En el espacio Quijotal". También registrar la desesperación del detenido o desaparecido injustamente en "Ante los ojos de Joseph K.", alusión al absurdo kafkiano. O encontrar relaciones entre la pintura y la poesía en el poema "Picasso" y entre la poesía y otras manifestaciones artísticas como en "A Carmen de Bizet". Y también íconos de la cultura popular contemporánea como el compositor, músico y cantante John Lennon en "La hora de John", entre otros referentes.

Sin duda, otro de los incentivos de esta vasta poética se encuentra en la exasperada expresión de un humano en permanente rebeldía contra la persistencia 
de factores de deshumanización. Los reclamos, entonces, no solo son sociales, en el sentido de enfrentar un sistema social. Hay de eso, es cierto. Pero van más allá. Es una intensa recusación ante todo tipo de mecanismos que flagelan a los más débiles, a los anónimos e ignorados de la historia. Poemas como "Área de salud" ("no respire / no se mueva / salga / un portero / cierra la conjunción / de la tristeza / murmullo / de enigma / en el silencio / un grito / recién nacido / sopla / identificado con las horas / el día ha comenzado / (la conciencia del país / está narcotizada)") o "Bandera de pueblo joven" ("Eres el privilegio de quien te mira... / Eres el brazo desnudo / que oprime al aire / Eres el incesante grito / de los despedazados a navaja / Eres la gota que cuenta la sed / que nos devora") son magníficas exposiciones poéticas de esta aseveración. La profesora universitaria Gissela Gonzáles Fernández, autora de la introducción del libro que reseño, advierte en estas preocupaciones "La actitud de abierta polémica (otra característica recurrente) que halla pleno desarrollo en el compromiso social del yo poético [...] involucrado en todas las dimensiones de ser humano".

La historia del territorio en el que se afincan desasosiegos y anhelos aparece reiteradamente. Por ejemplo, en "Cronología extensa", largo poema dedicado al jurista y amigo Alberto Ruiz Eldredge Rivera, se poetiza, a la manera de un recuento, hechos de la historia peruana y que concluye con versos que son apelación a una indudable esperanza: "Claridad con el día Claridad / dentro de todos y para todos / No digo / que la consigna figure / sino / Avancemos / a ritmo de paso humano. / El sol dispersa la canción de la alegría / a puro brillo / sobre la tierra".

Este repertorio de dilatados registros actualiza igualmente expresiones líricas que son respuestas del yo poético a las amenazas de cosificación de lo humano latentes en la tecnolatría avizoradas precozmente a inicios de los años setenta. Por ejemplo, el poema "Basta paren" dedicado a un conjunto de trabajadores del área de informática de una entidad, en el que leemos: "Basta / paren / central de procesamiento de datos electrónicos / sistema I.B.M. made in USA / Dentro de mí oigo el traqueteo / de sus máquinas / Fuera de mí el hombre es reemplazado 
/ Pasan conmigo uno a uno los dígitos / Yo no soy el hombre que dirige / [...] Un espacio de sonidos / y código modular al nombre / otro espacio de sonidos / y computadoras 3/70 al cerebro / traqueteo traqueteo traqueteo / se establecen análisis de sistemas / no llega el sol a la cara...”. Con justa razón Gissela Gonzáles advierte una tendencia reflexiva, producto de la "aguda observación del entorno".

Como han señalado muchos de los que se han acercado a la obra de Falla Barreda, sin dejar el uso del "lenguaje de todos los días" — característica formal de los poetas surgidos desde finales de los años sesenta-, la madura reflexión sobre el acto de la escritura es presencia insistente en los textos. El bello poema "Rosas" es una suerte de extensa arte poética celebrada en especial por el gran poeta peruano Xavier Abril en una carta personal publicada en 1982 en el número 12 de la revista Gleba:

He tardado en volver a sus páginas, a sus poemas [...] la circulación de las rosas más intrépidas y militantes que me ha tocado la suerte conocer y admirar, a la inversa de las otras rosas circunstanciales que no dieron motivo de padecimiento al hombre, al creador de sí mismo, sino a los confiados en la divinidad, palabra esta que, si no fuese idiota sería de todas manera, el factor de escape de todas las minucias.

En torno a esta capacidad de pensar y repensar la escritura, la profesora Gonzáles anota la presencia de "hondas y desgarradas reflexiones sobre el acto de la creación”. Ilustra al respecto la forma en que esta reflexión opera en el poema "Exposición emotiva", y precisa que "si bien al comienzo se señala la importancia del referente, rápidamente se toma conciencia de la insuficiencia de la palabra para explicarlo". Y cita: "Y verso / y verso / en medio de la calle / contemplando el invisible paso del llanto / de un hombre con la cara al suelo / que al mirar su sombra / descubre la lengua de los que viven por gusto / Y verso y verso / con la palabra en la boca / frente a un cartel de ortografía dudosa / y me falta ánimo / frente a los que cavan el aire / y me falta verso / y me falta llanto".

El tema clásico del "yo soy otro" expresado por Rimbaud se actualiza en el poema "Centinela", el ser social y el creador en contrapunto deja a este último 
“absorto por los sucesos de la voz". La poesía se constituye en un escudo que brinda cobertura, protege: “... en mis dolientes y dispersos poemas / se hace visible el centinela / que mira sin límites el ímpetu de la esperanza / que día a día / me hace mejor / ante el presente y las disoluciones del tiempo que lo habita / [...] / Mi casa tiene un centinela / como todo lo minúsculo que el silencio guarda / Sé quién es / pero no sé de dónde vino / ni por qué me cuida de los ruidos del mundo".

Es necesario también anotar que en cada uno de los libros reunidos, el hablante lírico expone, a la manera de una composición musical, diversas variaciones en torno al tema amoroso y de los afectos en general. Con frecuencia, como lo han advertido los que han abordado a lo largo del tiempo esta poesía, el sentimiento toma forma de artes poéticas.

Poesía abierta. Poemas reunidos de Ricardo Falla Barreda se constituye en un texto artístico literario que documenta una voz poética nacida en la segunda mitad del siglo XX que no ha dejado de expandirse y diversificarse dando cuenta de una fecunda labor. Fundador en 1965 del Grupo Gleba Literaria, director de la Revista Nueva Humanidad, activo miembro de la primera promoción de poetas que dieron forma a la poesía de los años setenta, Ricardo Falla Barreda es un autor indiscutible de la poesía peruana. Así lo patentiza este libro publicado por el Fondo Editorial de la UNMSM.

\section{Sonia Luz Carrillo Mauriz}

Universidad Nacional Mayor de San Marcos, Lima, Perú

Contacto: 1carrillom@unmsm.edu.pe

https://orcid.org/0000-0003-1513-7862 